\title{
Supporting Information: Implications of transitioning from de facto to engineered water reuse for power plant cooling
}

\author{
Zachary A. Barkera \& Ashlynn S. Stillwella,* \\ aCivil and Environmental Engineering, University of Illinois at Urbana-Champaign; \\ Urbana, IL, USA
}

*To whom correspondence should be addressed.

Email: ashlynn@illinois.edu

Phone: 217-244-6507, fax: 217-333-0687

6 pages, 2 tables, 3 figures

\section{Method}

To calculate the cost of constructing cooling towers, literature values summarized in Table $\mathrm{S} 1$ are used.

Table S1. Estimated unit costs for retrofitting with cooling towers

\begin{tabular}{|c|c|c|c|}
\hline \multirow[b]{2}{*}{ Fuel } & \multicolumn{2}{|c|}{ Capital Cost (US $\$ / M W)^{a}$} & \multirow[b]{2}{*}{ Reference } \\
\hline & Low & High & \\
\hline Coal & US $\$ 85,600$ & US\$95,100 & Zhai and Rubin (2010) ${ }^{1}$ \\
\hline Nuclear & US $\$ 205,000$ & US $\$ 1,240,000$ & $\begin{array}{l}\text { WorleyParsons }(2008)^{2} ; \\
\text { Asbury Park Press }(2010)^{3}\end{array}$ \\
\hline & \multicolumn{2}{|c|}{ O\&M Cost (US\$/Mgal) } & \\
\hline Cooling Tower & \multicolumn{2}{|c|}{ US $\$ 984$} & Walker et al (2013) 4 \\
\hline
\end{tabular}




\section{Case study}

Symbolizing the median wastewater production and power plant withdrawals, shown in Figure S1, we gain perspective about the quantity and location of demands and supplies. Most important is the conclusion that most of the wastewater treatment plants are upstream of the power plants. Additionally, wastewater is very abundant in this region.

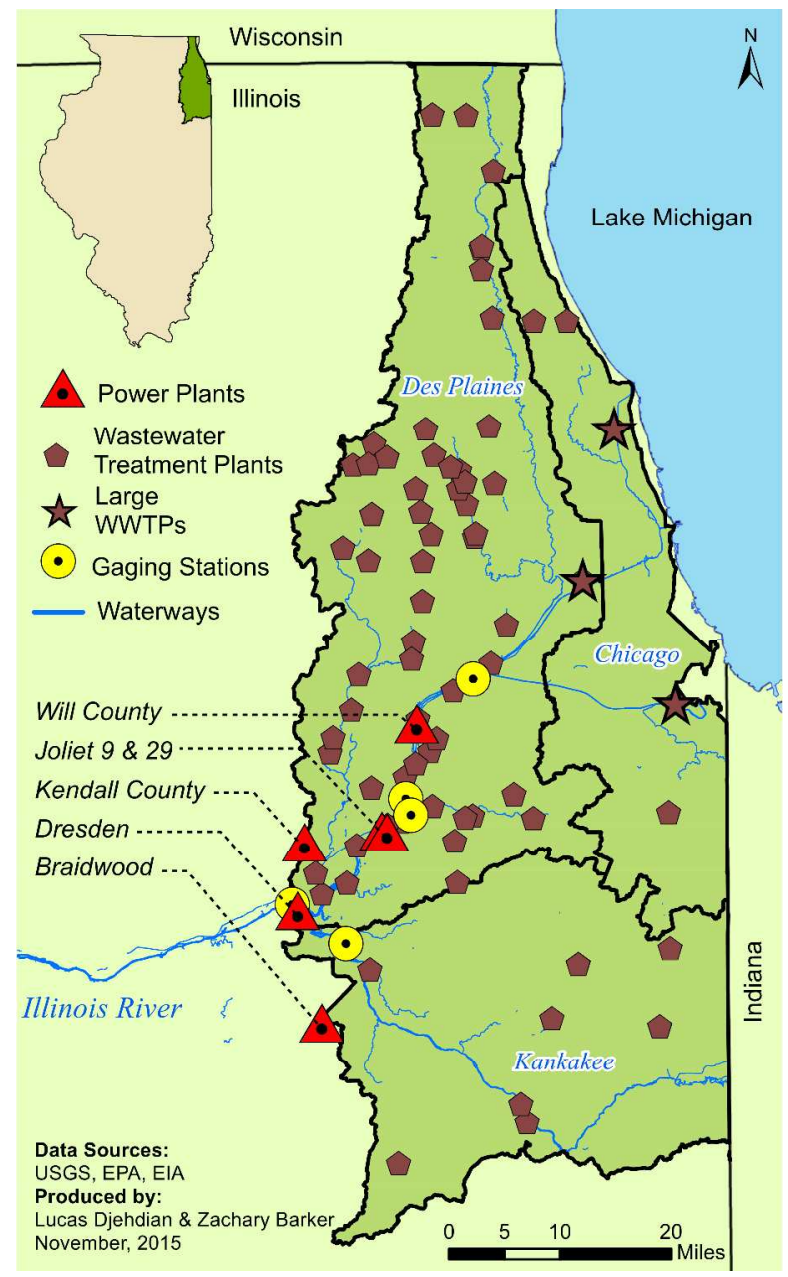

Figure S1: Data for the analysis included effluent from 72 wastewater treatment plants, withdrawals at six power plants, streamflow at 5 gauges, and terrain for three HUC-8 watersheds.

\section{De facto reuse}

First we calculate the median de facto reuse at each plant using the same technique as Rice et al.6,7 Shown in Figure S2, we find that de facto reuse is very high compared to national averages and increases with proximity to the City of Chicago. 


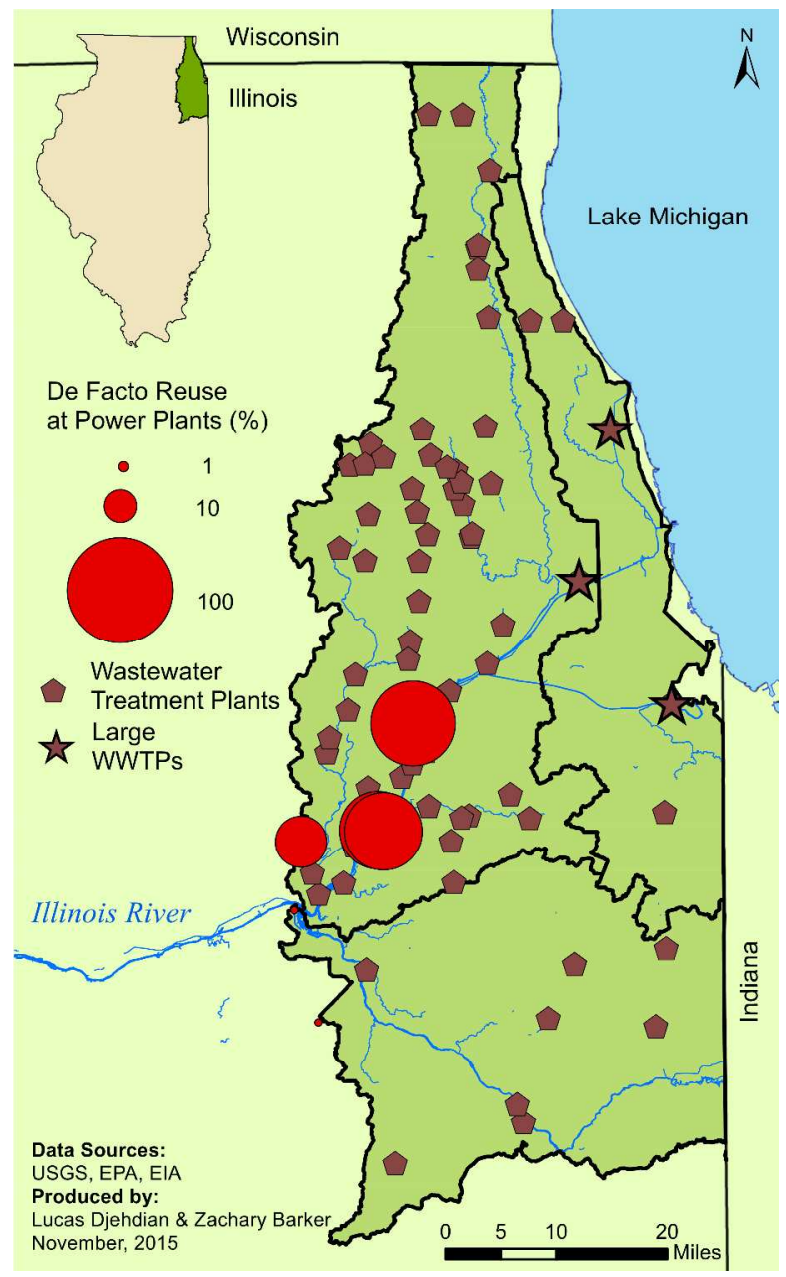

Figure S2: The de facto reuse, as calculated with the medians, increases with proximity to the large wastewater treatment plants. The two nuclear power plants have minimal de facto reuse percentages due to significantly less wastewater discharges in the Kankakee basin.

\section{Engineered reuse}

Shown if Figure $\mathrm{S}_{3}$, the cost scaling raster combines land use and slope data. Using the created raster, we find the least cost path between each power plant and each wastewater treatment plant. To determine which pipeline paths should represent our engineered reuse solution, we export the scalers associated with each pipeline via the Python library associated with ArcMap. We employ a genetic algorithm rather than a non-linear solver to avoid subjective prioritization in reclaimed water allocations and to create a more robust optimization to minimize total cost. Inputs are the lengths and cost scalers for each pipeline path and the solution is constrained by the supply and demands of reclaimed water. The decision variables are the diameters of each pipe; therefore, a diameter of zero represents a pipeline not built. Note that the genetic algorithm does not include an accounting mechanism for overlapping pipes that would likely be combined into one larger pipe in practice. The advanced computational power of the genetic 
algorithm provides sufficient flexibility to capture straightforward and more complex results such that the method is broadly applicable in other locations.

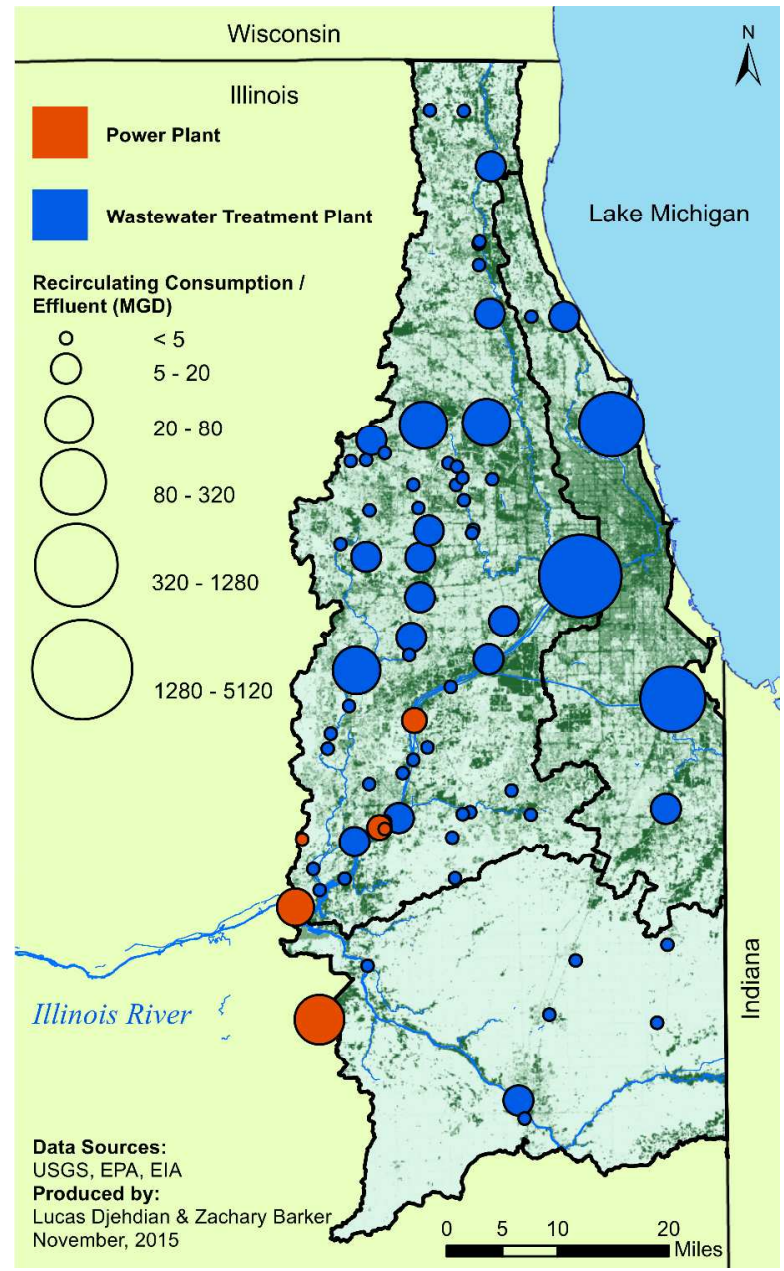

Figure S3: Retrofitting the power plants to closed-loop cooling systems reduces the water demand such that using the cost scaling raster, the least cost path between wastewater treatment plants and power plants can be found.

\section{Cost}

The results of our genetic algorithm are summarized in Table S2. The cost model, adapted from Zhang et al (2003) ${ }^{8}$ and Stillwell \& Webber (2014) ${ }^{9}$, computes cost as a function of diameter, land use, and slope. However, on average the first order estimate is about $\$ 3.8$ million per mile. 
Table S2: Estimated diameters and lengths of pipeline necessary are listed for conveying reclaimed water from the Stickney Water Reclamation Plant to the six power plants in the study area.

\begin{tabular}{rr}
$\begin{array}{c}\text { Diameter } \\
(\mathrm{ft})\end{array}$ & \multicolumn{1}{c}{$\begin{array}{c}\text { Length } \\
(\mathrm{mi})\end{array}$} \\
\hline 6.7 & 17.3 \\
6.6 & 14.0 \\
5.1 & 21.2 \\
5.0 & 3.0 \\
4.6 & 11.8 \\
2.0 & 2.5 \\
2.0 & 3.2 \\
0.5 & 20.0 \\
\hline
\end{tabular}

\section{Performance}

We estimate power for reclaimed water pumping using conservation of energy, accounting for major (friction) losses with the Hazen-Williams equation shown in Equation $\mathrm{S} 1$ : $^{10}$

$q_{w}=193.7 C D^{2.63}\left(\frac{h_{l}}{L}\right)^{0.54}$

where $q_{w}$ is the flow of reclaimed water [gpm], $C$ is the Hazen-Williams roughness coefficient, $D$ is diameter [feet], $h_{l}$ is the head loss [feet], and $L$ is the length of pipe [feet]. The life span of the system is assumed to be greater than 30 years; therefore, a conservative $C$ value of 100 is used. We calculate the diameter of each pipe assuming a hydraulic slope, representing the ratio between head loss and length, of 0.003 . Combining elevation changes and major friction losses, we estimate the power requirements for reclaimed water pumping as:

$P=k \frac{\gamma q h}{\eta}$

where $P$ is the pumping power [MW], $k$ is a units conversion constant equal to $331,041,912, \gamma$ is the specific weight of water [lb/ft3], $q$ is flow [gpm], $h$ is the total head required [feet], and $\eta$ is the combined efficiency of the pump and motor.

\section{References}

(1) Zhai, H. \& Rubin, E. S. Performance and cost of wet and dry cooling systems for pulverized coal power plants with and without carbon capture and storage. Energy Policy 2010, 38(10), 5653-5660. 
(2) WorleyParsons. FPLE - Beacon Solar Energy Project Dry Cooling Evaluation. WorleyParsons. 2008, FPLS-O-LI-450-0001. Folsom, CA.

(3) Asbury Park Press. Oyster Creek to close 10 years early, in 2019. Asbury Park Press. 2010, Neptune, NJ.

(4) Walker, M. E.; Theregowda, R. B.; Safari, I.; Abbasian, J.; Arastoopour, H.; Dzombak, D. A.; Hsieh, M. K.; Miller, D. C. Utilization of municipal wastewater for cooling in thermoelectric power plants: Evaluation of the combined cost of makeup water treatment and increased condenser fouling. Energy 2013, 60 (February), 139-147.

(5) Stillwell, A. S.; Webber, M. E. Novel methodology for evaluating economic feasibility of low-water cooling technology retrofits at power plants. Water Policy 2013, 292-308.

(6) Rice, J.; Westerhoff, P. Spatial and Temporal Variation in De Facto Wastewater Reuse in Drinking Water Systems across the U.S.A. Environ. Sci. Technol. 2014, 49 (2), 982-989.

(7) Rice, J.; Wutich, A.; Westerhoff, P. Assessment of de facto wastewater reuse across the U.S.: Trends between 1980 and 2008. Environ. Sci. Technol. 2013, 47, 11099-11105.

(8) Zhang, W.; Chung, G.; Pierre-Louis, P.; Bayraksan, G.; Lansey, K. Reclaimed water distribution network design under temporal and spatial growth and demand uncertainties. Environ. Model. Softw. 2013, 49, 103-117.

(9) Stillwell, A. S.; Webber, M. E. Geographic, technologic, and economic analysis of using reclaimed water for thermoelectric power plant cooling. Environ. Sci. Technol. 2014, 48 (8), 4588-4595.

(10) Mays, L. W. Water Resources Engineering, 2nd ed.; John Wiley \& Sons, Inc: Hoboken, NJ, 2011. 